\title{
Clinical complete responders to definite chemoradiation or radiation therapy for oesophageal cancer: predictors of outcome
}

Antoine Adenis ${ }^{1,2^{*}}$, Emmanuelle Tresch $^{3}$, Sylvain Dewas ${ }^{4,5}$, Olivier Romano ${ }^{1,4}$, Mathieu Messager ${ }^{6}$, Eric Amela ${ }^{1}$, Stéphanie Clisant ${ }^{7}$, Andrew Kramar ${ }^{3}$, Christophe Mariette ${ }^{5,6}$ and Xavier Mirabel ${ }^{1,4}$

\begin{abstract}
Background: To identify predictors of long-term outcome for patients with clinical complete response (cCR) after definite chemoradiotherapy (CRT) or radiation therapy (RT) for oesophageal cancer (EC).

Methods: In this retrospective study, we reviewed the files of all patients from our institution that underwent definitive RCT or RT for EC, from January 1998 to December 2003. Among 402 consecutive patients with EC, 110 cCR responses were observed, i.e. without evidence of tumour on morphological examination of the biopsy specimens, 8 to 10 weeks after radiation. Baseline patient and tumour characteristics were as follows: male $=98 / 110$, median age $=60$, squamous histology $=103 / 110$, tumour site (upper $/$ middle/lower third) $=41 / 50 / 19$, weight loss none $/<10 \% / \geq 10 \%=36 / 45 / 29$, dysphagia grade $1 / 2 / \geq 3=30 / 14 / 66$. Patients were staged according to endosonography and/or computed tomography. There were 9 stage I, 31 stage IIA, 15 stage IIB, 41 stage III, 6 stage IV. Post treatment nutritional characteristics were as follows: weight loss during treatment none $/<10 \% \geq 10 \%=35$ / $38 / 37$, remaining dysphagia grade $1 / 2 / \geq 3=54 / 24 / 32$. Univariate and multivariate analyses were performed using log-rank and Cox proportional hazards models, and survival curves were estimated using the Kaplan-Meier method.

Results: During follow up (median: 6 [0.4-9.8] years), 16 patients had salvage surgery. Median OS was 2.5 years, and 5-year OS was 33.5\%. Histological type, stage, age, gender, and treatment characteristics had no significant impact on outcome. The risk of death was increased two-fold for patients with grade $\geq 3$ dysphagia after treament $(H R=1.9[1.2-3.1], p=0.007)$. Weight loss $\geq 10 \%$ during treatment also negatively affected outcome $(H R=1.8$ $[1.0-3.2], p=0.040)$.
\end{abstract}

Conclusion: One EC patient among 3 with CCR after definite CRT/RT is still alive at 5 years. Variables related to reduced OS were: remaining significant dysphagia after treatment and weight loss $\geq 10 \%$ during treatment.

Keywords: Oesophageal cancer, Chemoradiotherapy, Radiation therapy, Prognosis

\section{Background}

Oesophageal cancer (EC) is a devastating malignancy which ranks $6^{\text {th }}$ on the list of cancer-mortality causes [1]. Pooled data from European registries indicate that 1-year and 5year overall survival (OS) rates are $33 \%$ and $10 \%$, respectively [2].

\footnotetext{
* Correspondence: a-adenis@o-lambret.fr

${ }^{1}$ Gastrointestinal Oncology Department, Centre Oscar Lambret, 3 rue Combemale, 59020 Lille Cedex, France

${ }^{2}$ Catholic University, 60 Boulevard Vauban, 59800 Lille, France

Full list of author information is available at the end of the article
}

Surgery continues to be the mainstay of treatment for patients with localised and locally advanced EC in the absence of medical contraindications [3] with a 5-year survival rate as high as $47 \%$ in a large-volume referral centre [4]. With respect to survival outcome and also from an organ preservation standpoint some patients may benefit from a program excluding surgery since the pioneer publication of the Radiation Therapy Oncology Group (RTOG) [5] which showed that $26 \%$ (95\% confidence interval (CI): 15\%-37\%) of patients treated with CRT (as compared to radiation only) were still alive at 5 years [6].

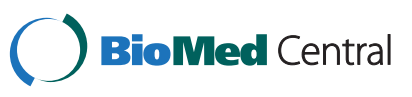


Because complete response (CR) $[7,8]$ is a major predictor of outcome for EC treated with definite CRT, many efforts have been made these last years, to define just what CR corresponds to [9], and to increase the rate of CR with new CRT regimens $[10,11]$. CR assessed by endoscopy has been chosen by investigators in recent prospective trials $[9,11]$ because of its validity as a good surrogate marker for OS $[12,13]$, and because of the unsatisfactory accuracy of CT scan and endoscopic ultrasonography (EUS) in the restaging after CRT $[13,14]$. Moreover, the decision-making impact of endoscopic biopsies remains questionable, due to the high false negative rate of this procedure [15-17].

The CR rate as the primary endpoint of a prospective trial for evaluating treatment of patients with EC has not been specifically studied, and there is sparse data about the specific outcome of these patients other than the fact that they have a greater chance to survive. In surgical series, the rate of ypTONOM0 (i.e. pathologic CR) after preoperative CRT is about $20-30 \% \%[4,18,19]$, and this group of patients may achieve an excellent 5-year survival as high as 55\%, with the best outcome for younger patients [19]. Using clinical tools-with their poor sensitivity-for clinical restaging, results from some studies showed that clinical CR (cCR) rates varied from $30 \%$ to $62 \%[10,11,20-22]$, depending on the time period of treatment, imaging modalities (with or without post treatment biopsies), and, obviously, on treatments. OS of patients with $\mathrm{cCR}$ has not been specifically addressed, and their determinants of outcome are mostly unknown.

In the current study, we reviewed our series of 110 patients with $\mathrm{CCR}$ who were treated with definite RCT or radiotherapy (RT) for EC, and staged by available clinical means, in order to identify prognostic factors that predict their long-term outcome.

\section{Methods}

\section{Patient population}

From January 1998 to December 2003, 402 consecutive patients with localized or locally advanced EC underwent definite CRT or RT at the Centre Oscar Lambret (Northern France Cancer Centre, Lille). One hundred ten patients with $\mathrm{cCR}$ (27\%) formed the basis of this study, which was conducted according to the Helsinki declaration and the national French laws for retrospective monocentric studies (Commission Nationale Informatique et Liberté agreement 1034071 , Sept $\left.27^{\text {th }}, 2004\right)$, and registered in http://clinicaltrials.gov (NCT01525953).

\section{Pretreatment evaluation}

Pretreatment evaluation included physical examination, barium swallow, and endoscopy of the oesophagus, and thoracic and abdominal CT and/or EUS. Patients were classified with EUS according to the 1997 AJCC staging system [23], and/or with CT according with the so- called modified Wurtz classification [24] which makes a CT-defined T3 (ct-T3) a tumour whose largest diameter is over $30 \mathrm{~mm}$, without suspicion of adjacent organ involvement. In this CT classification, lymph nodes are considered malignant if their largest diameter is over $10 \mathrm{~mm}$.

Fluorodeoxyglucose positon emission tomography was not used. Dysphagia was evaluated according to the Atkinson's classification: grade 1, ability to eat a normal diet; grade 2, ability to eat some solid food; grade 3 , ability to eat some semisolids only; grade 4, ability to swallow liquids only; grade 5, complete dysphagia [25].

\section{Treatment details}

RT was delivered with megavoltage equipment (> $8 \mathrm{MV}$ ) using a multiple field technique. Patients were treated 5 days per week and most of them received $1.8 \mathrm{~Gy} / \mathrm{d}$ in 28 fractions (total dose: $50.4 \mathrm{~Gy}$ ). The total RT dose to the spinal cord was limited to 40 Gy. Patients were treated through a 3 or 4 fields technique with all fields treated each day. Prescription doses were specified at the International Commission on Radiation Units and Measurements Report 50 reference point. The superior and inferior borders of the radiation fields were $3 \mathrm{~cm}$ beyond the primary tumor. The lateral, anterior, and posterior borders of the fields were $2 \mathrm{~cm}$ beyond the borders of the primary tumor. The primary and the regional lymph nodes were included into the radiation fields as were supraclavicular lymph nodes and celiac lymph nodes for tumors of the upper esophagus and lower esophagus, respectively.

All patients underwent the cytotoxic schedule of the so-called "RTOG regimen" [5] except those who were treated on a phase I protocol with weekly vinorelbine in conjunction with RT (64 Gy, 2 Gy per fraction) [26], and patients whose medical condition did not allow for 5fluorouracil and/or platinum salts administration.

\section{Follow-up evaluation}

Patients were planned to be re-staged 8 to 10 weeks after the end of radiation, that is more or less 3-4 weeks after the last chemotherapy dosing. Post treatment evaluation included physical exam, upper endoscopy plus biopsies and thoracic and abdominal CT scan. Complete clinical responders were defined as patients without evidence of tumour on physical examination, on endoscopy, on oesophageal biopsies, and on CT scan. Follow-up consisted of an upper endoscopy yearly, or earlier if clinically indicated. Subsequent thoracic and abdominal CTs were not routinely obtained unless clinically indicated. Patterns of treatment failure were defined as the first site of failure. Regional failure included the primary tumour and the regional lymph nodes. 
Follow-up data were obtained from medical records and referring physicians.

\section{Statistics}

Patient characteristics were described with median and extreme values for continuous variables and with frequencies and percentages for categorical variables. All event times were calculated from the last day of radiation therapy. Survival was assessed with the KaplanMeier method. The influence of categorical variables on survival was investigated with the Log-Rank test for univariate analyses, and the Cox proportional hazards model was used for multivariate analyses. To obtain a prognostic score, an integer weight was assigned proportional to the regression coefficients of each significant variable obtained from the multivariate Cox model and then combined to obtain an overall score. The number of prognostic categories was grouped together using a hierarchal coding system. The predictive discrimination of the model was evaluated with Harrell's C statistic.

\section{Results}

\section{Patient and treatment characteristics}

There were 98 men and 12 women, and age ranged from 37 to 85 years $($ median $=60)$. Patient and treatment characteristics are presented in Table 1 . Most patients $(74 / 110)$ presented with significant weight loss (WL) at baseline: 29 patients $(26.4 \%)$ had lost more than $10 \%$ of their body-weight, 28 (25.5\%), had lost between 6 to $10 \%$, and 17 (15.5\%) had lost less than 5\%. 30/110 patients $(27.5 \%)$ presented without any dysphagia (grade $1)$, and $14(12.8 \%)$, $54(49.5 \%), 8(7.3 \%)$, and $3(2.8 \%)$ presented with grade 2 , grade 3 , grade 4 , or grade 5 dysphagia respectively. There were 9 stage I, 31 stage IIA, 15 stage IIB, 41 stage III, 6 nodal stage IV. In 8 cases, we were not able to retrieve enough good quality data to assess the tumour stage. Most of the patients received the RTOG regimen [5] with 50.4 Gy in 28 fractions, plus 2 cycles of concurrent chemotherapy (5-fluorouracil-cisplatin), then 2 cycles of sequential chemotherapy. Even though our patients were treated with the primary aim of definite CRT, there is a subset of 16 patients who subsequently had oesophagectomy for local recurrence $(\mathrm{n}=3)$, or for some other reason (remaining dysphagia $=2$; patient's wish after open discussion with his surgeon $=13$ ). Some patients $(75 / 110)$ presented with significant WL at restaging (vs baseline): 37 patients had lost more than $10 \%$ of their body-weight, 25 had lost between 6 to $10 \%$, and 13 had lost less than 5\%. At restaging, 54/110 patients (49.1\%) presented without any dysphagia, and 24 (21.8\%), 18 (16.4\%), 8 (7.3\%), and 6 (5.5\%) presented with grade 2 , grade 3 , grade 4 , or grade 5 dysphagia respectively. An improvement in dysphagia was only seen
Table 1 Patients and treatment characteristics

\begin{tabular}{|c|c|c|}
\hline $\mathrm{N}=110$ & $\mathrm{n}$ & $\%$ \\
\hline \multicolumn{3}{|l|}{ Gender } \\
\hline M & 98 & $89.1 \%$ \\
\hline $\mathrm{F}$ & 12 & $10.9 \%$ \\
\hline \multicolumn{3}{|l|}{$\overline{\text { Age }}$} \\
\hline$\leq 60$ & 60 & $54.5 \%$ \\
\hline$>60$ & 50 & $45.5 \%$ \\
\hline \multicolumn{3}{|l|}{ Histology } \\
\hline Adenocarcinoma & 7 & $6.4 \%$ \\
\hline Squamous cell & 103 & $93.6 \%$ \\
\hline \multicolumn{3}{|l|}{ Tumour site } \\
\hline Upper third & 41 & $37.3 \%$ \\
\hline Middle third & 50 & $45.5 \%$ \\
\hline Lower third & 19 & $17.3 \%$ \\
\hline \multicolumn{3}{|l|}{ Staging (CT or EUS) $(n=102)$} \\
\hline I & 9 & $8.8 \%$ \\
\hline$\| \mathrm{A}$ & 31 & $30.4 \%$ \\
\hline$\| \mathrm{B}$ & 15 & $14.7 \%$ \\
\hline III & 41 & $40.2 \%$ \\
\hline IV & 6 & $5.9 \%$ \\
\hline \multicolumn{3}{|l|}{ Radiation (Gy) } \\
\hline$<50.4$ & 3 & $2.7 \%$ \\
\hline 50.4 & 58 & $52.7 \%$ \\
\hline$>50.4$ & 49 & $44.5 \%$ \\
\hline Chemotherapy & 95 & $86.4 \%$ \\
\hline Cisplatin + Fluorouracil & 91 & $82.7 \%$ \\
\hline Other* & 4 & $3.7 \%$ \\
\hline Surgery & 16 & $14.5 \%$ \\
\hline For recurrence & 3 & $2.7 \%$ \\
\hline For remaining dysphagia & 2 & $1.8 \%$ \\
\hline $\begin{array}{l}\text { Patient's wish after open discussion with his surgeon, } \\
\text { after chemoradiation }\end{array}$ & 11 & $10 \%$ \\
\hline Endoprosthesis & 10 & $9.1 \%$ \\
\hline Before radiation & 9 & $8.2 \%$ \\
\hline After radiation & 1 & $0.9 \%$ \\
\hline Dilatation & 16 & $14.5 \%$ \\
\hline Before radiation & 14 & $12.7 \%$ \\
\hline After radiation & 2 & $1.8 \%$ \\
\hline
\end{tabular}

*carboplatin: 1, cisplatin: 1, vinorelbine: 2 .

in one half of the patients $(55 / 110)$, while $22 / 110$ patients $(20.2 \%)$ presented with worsened dysphagia.

\section{Survival analysis, pattern of treatment failure, prognostic factors}

With a median follow-up period of 6.0 years (range: 0.4 to 9.8 years), the median OS was 2.5 years. Three-and five-year OS rates were $46.9 \%$, and $33.5 \%$, respectively. A 
subgroup analysis of patients who had surgery $(n=16)$ revealed a median survival of 2.7 years (versus 2.5 years for the other 94 patients) (Figure 1). Forty-four patients (40\%) experienced treatment failure. These recurrences were local only in 26 cases, distant only in 12 cases, and local and distant in 6 cases. Twenty recurrences (45.5\%) occurred within the radiation field. Twenty-three patients $(20.9 \%)$ experienced a second metachronous cancer. The presence of dysphagia after treatment, and WL during treatment were identified as significant predictors of poor OS in univariate and multivariate analysis (Table 2). The risk of death was increased two-fold for patients with weight-loss over $10 \%$ during treatment ( $\mathrm{HR}=1.8$ [1.0-3.2], $\mathrm{p}=0.04$ ) (Figure 2) and for patients with grade $\geq 3$ dysphagia after treatment $(\mathrm{HR}=1.9$ [1.23.1], $\mathrm{p}=0.007)$. Histological type, stage, age, gender, weight-loss at baseline, and treatment characteristics did not show a significant influence on outcome. In our study, we were able to identify 3 groups of patients with different prognosis, depending on whether or not patients had, WL during treatment (score $=1$ if $\mathrm{WL}<10$ and score $=2$ if $\mathrm{WL} \geq 10 \%$ ) and/or remaining dysphagia after treatment $($ score $=2)$. Good prognosis patients had a score of zero (26 pts, median OS $=5.8$ ), intermediate prognosis patients a score of 1 ( 28 pts, median $\mathrm{OS}=2.7$ ) and poor prognosis patients had a score of at least $2(56$ pts, median $\mathrm{OS}=1.3$ ). Harrell's $\mathrm{C}$ index was equal to 0.656 .

\section{Discussion and conclusion}

The main results from this long-term follow-up study with a prognostic factor analysis is that one EC patient out of 3 with cCR after definite CRT/RT is still alive 5 years after the end of treatment. This curative intent was achieved in a series of patients with mainly locally advanced EC. The bad news is that it occurred for a minority of patients only, in a subclass of EC who received definite

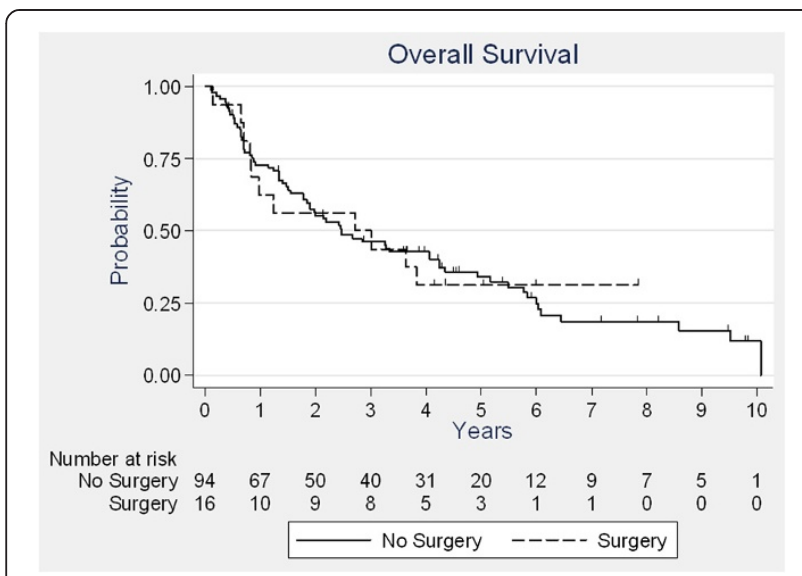

Figure 1 Overall survival according to surgery.
CRT/RT. Our rate of cCR (27\%) is a bit lower than what has been reported elsewhere (30 to 62\%) [10,11,20-22], and may be reflecting differences in patient and tumour characteristics, as well as the intensiveness and timing of restaging work-up, and finally as to the true definition of cCR. Despite the recent and debatable input of fluorodeoxyglucose positron emission tomography $[27,28]$ to standard work-up with morphological examination with biopsies, cCR remains difficult to assess accurately, because of the unsatisfactory sensitivity of CT and EUS, in the restaging after CRT $[13,14]$. Moreover, the negative predictive value of negative biopsies has been reported as comprised between $23 \%$ and 52\% [15,29]. We were not able to reproduce the survival rates published by Ishihara et al. [20] in their series of 110 EC who achieved cCR after CRT (3-year OS: $66 \%$ vs our 47\% [95\% CI: 37.2-56\%]), maybe due to patient selection or just because of a longer follow-up duration in our series. Obviously, we cannot compare our data to the excellent 55\% 5-year OS rate obtained after preoperative CRT in ypTONOMOR0 patients [19] selected on their ability to undergo surgery, and for whom the evaluation criteria (i.e. pathological CR) is far different from cCR.

It was disappointing for us to find that a majority of recurrences occurred within the radiation field, in this series of selected patients. We have to face the fact that it has been also reported elsewhere, either on retrospective or on prospective series [30-32].

This work is, to our knowledge, the first to report WL during treatment, and significant dysphagia after treatment as significant predictors of poor OS. It is implicitly known that remaining dysphagia after treatment may be related to persistent disease and implies a need for another treatment, even though it is difficult to distinguish it from an oesophageal stenosis caused by fibrosis or ischemic changes induced by RT. On that line, it is noteworthy that in the FFCD-9102 trial (CRT for locally advanced EC, then in case of clinical response, patients were randomised between CRT continuation or surgery) [33], some patients who were not randomised due to non response, no improved dysphagia, or other reason, were in pCR after subsequent surgery [34]. Therefore, remaining dysphagia after treatment does not seem a robust enough parameter for decision-making. DiFiore et al. [7] previously showed that baseline nutritional parameters (albumin serum level, body-mass index, dysphagia, or weight loss) were strong prognostic factors for survival, but in a series of patients treated with CRT, not in cCR only. We looked at the prognostic value of baseline albumin (data not shown), and we did not find any impact on survival. Because some of our patients had WL during treatment, we cannot rule out that our nutrition policy maybe was not watchful enough. On that line, some of our coauthors are strong advocates of 
Table 2 Overall Survival according to prognostic factors (upper table: univariate analysis, lower table: multivariate analysis)

\begin{tabular}{|c|c|c|c|c|c|c|c|c|c|}
\hline Prognostic factors & $\mathrm{N}$ & $\mathbf{n}$ & Median OS [Cl 95\%] & $p$ & Prognostic factors & $\mathbf{N}$ & $\mathrm{n}$ & Median OS [Cl 95\%] & $p$ \\
\hline Total & 110 & 80 & $2.5[1.8-4.1]$ & & & & & & \\
\hline \multicolumn{5}{|l|}{ Age } & \multicolumn{5}{|l|}{ Surgery } \\
\hline$<=60 y$ & 60 & 39 & 2. $5[1.8-6.0]$ & 0.060 & No & 94 & 69 & $2.5[1.8-4.2]$ & 0.97 \\
\hline$>60 y$ & 50 & 41 & 2. $7[1.1-4.1]$ & & Yes & 16 & 11 & $2.7[0.8-\ldots]$ & \\
\hline \multicolumn{5}{|l|}{ Gender } & \multicolumn{5}{|l|}{ Albuminemia } \\
\hline M & 98 & 71 & $2.5[1.8-4.1]$ & 0.92 & $<35 \mathrm{~g} / \mathrm{L}$ & 4 & 4 & $1.3[0.5-\ldots]$ & 0.20 \\
\hline $\mathrm{F}$ & 12 & 9 & $2.0[0.7-\ldots]$ & & $\geq 35 \mathrm{~g} / \mathrm{L}$ & 46 & 34 & $3.3[1.9-4.9]$ & \\
\hline \multicolumn{5}{|l|}{ Histology } & \multicolumn{5}{|l|}{ Dysphagia (baseline) } \\
\hline Adenocarcinoma & 7 & 7 & $2.5[0.6-4.1]$ & 0.17 & Grade 1-2 & 44 & 31 & $3.0[1.8-4.2]$ & 0.90 \\
\hline Squamous cell & 103 & 73 & $2.7[1.8-4.2]$ & & Grade $\geq 3$ & 65 & 48 & $2.7[1.5-4.4]$ & \\
\hline \multicolumn{5}{|l|}{ Tumor site } & \multicolumn{5}{|l|}{ Dysphagia (end of treatment) } \\
\hline Upper third & 41 & 30 & $4.2[2.0-5.8]$ & 0.23 & Grade 1-2 & 78 & 58 & $3.3[2.1-5.5]$ & 0.0016 \\
\hline Middle third & 50 & 35 & $1.9[1.2-3.0]$ & & Grade $\geq 3$ & 32 & 28 & $0.9[0.6-3.3]$ & \\
\hline Lower third & 19 & 15 & $2.5[0.7-3.3]$ & & & & & & \\
\hline \multicolumn{5}{|l|}{ Staging } & \multicolumn{5}{|l|}{ Weight loss at baseline } \\
\hline I/IIA & 40 & 28 & $3.3[1.3-5.8]$ & 0.074 & None & 36 & 22 & $5.2[1.8-6.1]$ & 0.20 \\
\hline$\|\mathrm{B} /\|$ & 56 & 41 & $2.5[1.5-3.8]$ & & $<10 \%$ & 45 & 35 & $1.9[1.2-3.0]$ & \\
\hline IV & 6 & 6 & $0.9[0.7-\ldots]$ & & $\geq 10 \%$ & 29 & 23 & $2.5[1.3-3.6]$ & \\
\hline \multicolumn{5}{|l|}{ Chemotherapy } & \multicolumn{5}{|l|}{ Weight loss during treatment } \\
\hline No & 15 & 11 & $2.0[0.7-4.2]$ & 0.36 & None & 35 & 21 & $5.5[2.7-8.6]$ & 0.039 \\
\hline Yes & 95 & 69 & $2.8[1.8-4.1]$ & & $<10 \%$ & 38 & 28 & $2.5[1.5-4.2]$ & \\
\hline \multicolumn{5}{|l|}{ Radiation dose } & $\geq 10 \%$ & 37 & 31 & $1.4[0.8-2.1]$ & \\
\hline$\leq 50.4$ Gy & 61 & 41 & $3.3[1.8-4.9]$ & 0.45 & & & & & \\
\hline$>50.4$ Gy & 49 & 39 & $2.0[1.1-4.2]$ & & & & & & \\
\hline Prognostic variables & Deatl & $\mathrm{hs} / \mathrm{N}$ & OS rate $[\mathrm{Cl} 95 \%]$ & & Median OS [Cl 95\%] (y) & HR [C & 95\%] & $\mathbf{p}$ & Score \\
\hline \multicolumn{10}{|l|}{ Weight loss during treatment } \\
\hline None & \multicolumn{2}{|c|}{$21 / 35$} & \multicolumn{2}{|l|}{$63 \%[45-77]$} & $5.5[2.7-8.6]$ & \multicolumn{2}{|c|}{1} & & 0 \\
\hline$<10 \%$ & \multicolumn{2}{|c|}{$28 / 38$} & \multicolumn{2}{|l|}{$46 \%$ [29-61] } & $2.5[1.5-4.2]$ & \multicolumn{2}{|c|}{$1.5[0.8-2.6]$} & 0.18 & 1 \\
\hline$\geq 10 \%$ & \multicolumn{2}{|c|}{$31 / 37$} & \multicolumn{2}{|l|}{$32 \%[18-48]$} & $1.4[0.8-2.1]$ & \multicolumn{2}{|c|}{$1.8[1.0-3.2]$} & 0.040 & 2 \\
\hline \multicolumn{10}{|c|}{ Dysphagia (end of treatment) } \\
\hline Grade 1-2 & \multicolumn{2}{|c|}{$52 / 78$} & \multicolumn{2}{|l|}{$52 \%[40-63]$} & $3.3[2.1-5.5]$ & \multicolumn{2}{|c|}{1} & & 0 \\
\hline Grade $\geq 3$ & \multicolumn{2}{|c|}{$28 / 32$} & $34 \%[19-51]$ & & $0.9[0.6-3.3]$ & $1.9[1$ & $-3.1]$ & 0.007 & 2 \\
\hline
\end{tabular}

artificial nutrition in patients undergoing CRT [35], although, the prognostic impact of nutrition has not yet been specifically addressed during CRT in that setting, When combining our 2 predictors of survival into a simple score, we obtained a doubling of median survival between the three groups for patients with none, one or two adverse factors. Whether or not this score may be use as a tool for decision-making, needs to be validated prospectively.

Obviously this study has some drawbacks. First, due to its retrospective nature, some clinical and biological data were not available in all cases, such as baseline CT and/or EUS staging, or baseline albumin or body-mass index. This missing information may have hampered the description of our cohort, and possibly the prognostic impact of some baseline characteristics. Second, the findings obtained from one center, in an area of rather high-incidence of squamous cells EC may not be directly extended to other countries, and needs to be refined in other settings. Third, we did not find any prognostic value of histology, stage, age or treatment characteristics, and we cannot rule out that it may be related to the small sample size of our series. Fourth, this is a long-term 

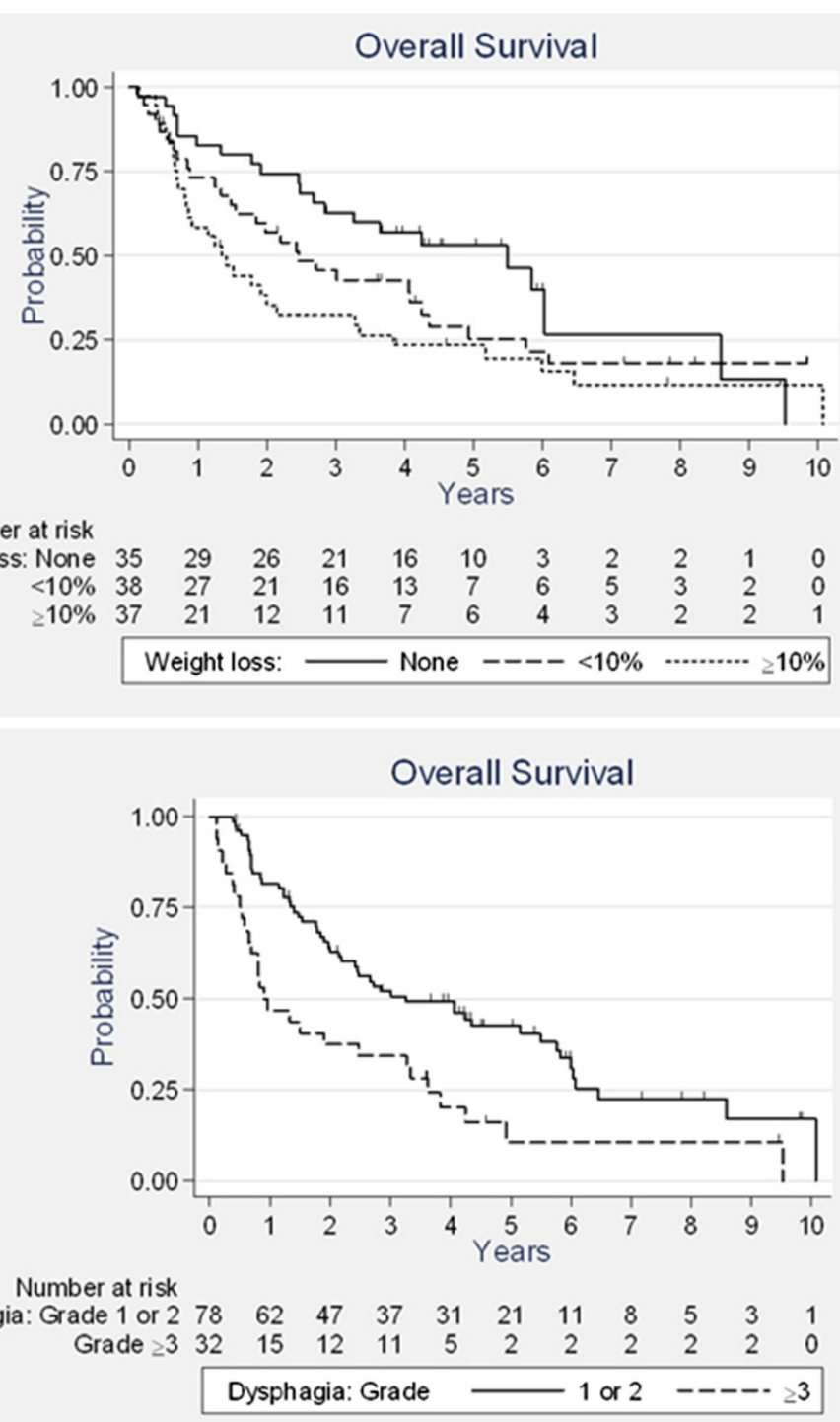

Figure 2 Overall survival according to weight loss during treatment (up), and grade of dysphagia after treatment (down).

survival analysis, and some patients had been treated more that 13 years ago, at a period of time where our nutritional support policy was not as well defined as nowadays. Finally, our patients were not homogenously treated, although only a minority of patients received RT alone (15/110), or had a CRT regimen different from the one from the RTOG (4/95), or who had surgery (16/ 110) whereas it was not initially planned. Interestingly, $49 / 110$ patients received higher radiation doses than the standard $50.4 \mathrm{~Gy} / 28$ fractions schedule, but this factor had no prognostic impact in this series.

This work reinforces available evidence that some EC may be cured by RCT/RT only $[6,31,33]$, even locally advanced ones. Whether or not patients may benefit from the correction of adverse prognostic factors such as weight loss during treatment, or dysphagia at the end of treatment by an intensive nutritional support during radiation or salvage surgery, respectively, needs to be prospectively assessed.

\section{Competing interests}

The authors declare that they have no competing interests.

\section{Authors' contributions}

AA and XM conceived the study. SC gave administrative support. ET carried out the statistical analysis and wrote the statistical report under the supervision of AK. MM and CM provided patients and surgical data. AA, SD, EA, XM provided patients, and collected data. OR collected data and drafted the manuscript. AA wrote the manuscript with the support of XM and CM. All authors read and approved the final manuscript.

\section{Author details}

${ }^{1}$ Gastrointestinal Oncology Department, Centre Oscar Lambret, 3 rue Combemale, 59020 Lille Cedex, France. ${ }^{2}$ Catholic University, 60 Boulevard Vauban, 59800 Lille, France. ${ }^{3}$ Methodology and Biostatistics Unit, Centre Oscar Lambret, 3 rue Combemale, 59020 Lille Cedex, France. ${ }^{4}$ Department of 
Radiotherapy, Centre Oscar Lambret, 3 rue Combemale, 59020 Lille Cedex, France. ${ }^{5}$ Lille University, Faculté de Médecine Henri-Warembourg, Lille Cedex 59045, France. ${ }^{6}$ Surgery Department, University Hospital, Hôpital C Huriez, Place de Verdun, 59037 Lille Cedex, France. ${ }^{7}$ Clinical Research Unit, Centre Oscar Lambret, 3 rue Combemale, 59020 Lille Cedex, France.

Received: 7 December 2012 Accepted: 19 August 2013

Published: 6 September 2013

\section{References}

1. Parkin DM, Bray F, Ferlay J, Pisani P: Global cancer statistics 2002. CA Cancer J Clin 2005, 55:74-108.

2. Faivre J, Forman D, Estève J, Obradovic M, Gatta G: Survival of patients with oesophageal and gastric cancers in Europe. Eur J Cancer 1998, 34:2167-2175

3. Mariette C, Piessen G, Triboulet JP: Therapeutic strategies in oesophageal carcinoma: role of surgery and other modalities. Lancet Oncol 2007. 8:545-553

4. Mariette C, Piessen G, Briez N, Triboulet JP: The number of metastatic lymph nodes and the ratio between metastatic and examined lymph nodes are independent prognostic factors in esophageal cancer regardless of neoadjuvant chemoradiation or lymphadenectomy extent. Ann Surg 2008, 247:365-371.

5. Herskovic A, Martz K, Al-Sarraf M, Leichman L, Brindle J, Vaitkevicius V, Cooper J, Byhardt R, Davis L, Emami B: Combined chemotherapy and radiotherapy compared with radiotherapy alone in patients with cancer of the esophagus. N Engl J Med 1992, 326:1593-1598.

6. Cooper JS, Guo MD, Herskovic A, Macdonald JS, Martenson JA Jr, Al-Sarraf M, Byhardt R, Russell AH, Beitler JJ, Spencer S, Asbell SO, Graham MV Leichman LL: Chemoradiotherapy of locally advanced esophageal cancer: long-term follow-up of a prospective randomized trial (RTOG 85-01): radiation therapy oncology group. JAMA 1999, 281:1623-1627.

7. Di Fiore F, Lecleire S, Pop D, Rigal O, Hamidou H, Paillot B, Ducrotté P, Lerebours $E$, Michel $P$ : Baseline nutritional status is predictive of response to treatment and survival in patients treated by definitive chemoradiotherapy for a locally advanced esophageal cancer. Am J Gastroenterol 2007، 102:2557-2563.

8. Lim JT, Truong PT, Berthelet E, Pai H, Joe H, Wai E, Larsson S, Kader HA, Weinerman B, Wilson K, Olivotto IA: Endoscopic response predicts for survival and organ preservation after primary chemoradiotherapy for esophageal cancer. Int J Radiat Oncol Biol Phys 2003, 57:1328-1335.

9. Tahara M, Ohtsu A, Hironaka S, Ku N, Ishikura S, Miyata Y, Ogino T, Yoshida $S$ : Clinical impact of criteria for complete response of primary site to treatment of esophageal cancer. Jpn J Clin Oncol 2005, 35:316-623.

10. Michel P, Adenis A, Di Fiore F, Boucher E, Galais MP, Dahan L, Mirabel X, Hamidou H, Raoul JL, Jacob JH, Hellot MF, Prod'homme S, Paillot B: Induction cisplatin-irinotecan followed by concurrent cisplatin-irinotecan and radiotherapy without surgery in oesophageal cancer: multicenter phase II FFCD trial. Br J Cancer 2006, 95:705-709.

11. Conroy T, Yataghene $Y$, Etienne PL, Michel P, Senellart H, Raoul JL, Mineur L, Rives M, Mirabel X, Lamezec B, Rio E, Le Prisé E, Peiffert D, Adenis A: Phase II randomized trial of definitive chemoradiotherapy with FOLFOX4 or cisplatin plus fluorouracil in first line treatment of patients with inoperable esophageal cancer. Br J Cancer 2010, 103:1349-1355.

12. Brown WA, Thomas J, Gotley D, Burmeister BH, Lim KH, Martin I, Walpole ET, Thomson DB, Harvey JA, Smithers BM: Use of oesophagogastroscopy to assess the response of oesophageal carcinoma to neoadjuvant therapy. Br J Surg 2004, 91:199-204.

13. Kalha I, Kaw M, Fukami N, Patel M, Singh S, Gagneja H, Cohen D, Morris J: The accuracy of endoscopic ultrasound for restaging esophageal carcinoma after chemoradiation therapy. Cancer 2004, 101:940-947.

14. Westerterp M, van Westreenen HL, Reitsma JB, R Ansari H, Kasza K, Szeto L, Vokes EE: Esophageal cancer: $\mathrm{CT}$, endoscopic US, and FDG PET for assessment of response to neoadjuvant therapy -systematic review. Radiology 2005, 236:841-851.

15. Triboulet JP, Amrouni H, Guillem P, Vandenhaute B, Lecomte-Houcke M, Adenis A: Long term results of esophageal epidermoïd cancer with complete remeission to preoperative chemoradiotherapy. Ann Chir 1998, 52:503-508.

16. Schneider PM, Metzger R, Schaefer $H$, Baumgarten F, Vallbohmer $D$, Brabender J, Wolfgarten E, Bollschweiler E, Baldus SE, Dienes HP, Hoelscher
AH: Response evaluation by endoscopy, rebiopsy, and endoscopic ultrasound does not accurately predict histopathologic regression after neoadjuvant chemoradiation for esophageal cancer. Ann Surg 2008, 248:902-908.

17. Sarkaria IS, Rizk NP, Bains MS, Tang LH, Ilson DH, Minsky BI, Rusch WW: Posttreatment endoscopic biopsy is a poor-predictor of pathologic response in patients undergoing chemoradiation therapy for esophageal cancer. Ann Surg 2009, 249:764-767.

18. Burmeister BH, Smithers BM, Gebski V, Fitzgerald L, Simes RJ, Devitt P, Ackland S, Gotley DC, Joseph D, Millar J, North J, Walpole ET, Denham JW, Trans-Tasman Radiation Oncology Group, Australasian Gastro-Intestinal Trials Group: Surgery alone versus chemoradiotherapy followed by surgery for resectable cancer of the oesophagus: a randomised controlled phase III trial. Lancet Oncol 2005, 9:659-668.

19. Vallböhmer D, Hölscher AH, DeMeester S, DeMeester T, Salo J, Peters J, Lerut T, Swisher SG, Schröder W, Bollschweiler E, Hofstetter W: A multicenter study of survival after neoadjuvant radiotherapy/chemotherapy and esophagectomy for ypTONOMORO esophageal cancer. Ann Surg 2010, 252:744-749.

20. Ishihara R, Yamamoto S, lishi H, Takeuchi Y, Sugimoto N, Higashino K, Uedo N, Tatsuta M, Yano M, Imai A, Nishiyama K: Factors predictive of tumor recurrence and survival after initial complete response of esophageal squamous cell carcinoma to definitive chemoradiotherapy. Int J Radiat Oncol Biol Phys 2010, 76:123-129.

21. Kato K, Muro K, Minashi K, Ohtsu A, Ishikura S, Boku N, Takiuchi H, Komatsu Y, Miyata Y, Fukuda H, Gastrointestinal oncology study group of the Japan clinical oncology group (JCOG): Phase II study of chemoradiotherapy with 5 -fluorouracil and cisplatin for stage II-III esophageal squamous cell carcinoma: JCOG trial (JCOG 9906). Int J Radiat Oncol Biol Phys 2011, 81:684-690

22. Suzuki A, Xiao L, Hayashi Y, Blum MA, Welsh JW, Lin SH, Lee JH, Bhutani MS, Weston B, Maru DM, Rice DC, Swisher SG, Hofstetter WL, Erasmus J, Ajani JA: Nomograms for prognostication of outcome in patients with esophageal and gastroesophageal carcinoma undergoing definitive chemoradiotherapy. Oncology 2012, 82:108-113.

23. Ellis FH Jr, Heatley GJ, Balogh K: Proposal for improved staging criteria for carcinoma of the esophagus and cardia. Eur J Cardiothorac Surg 1997, 12:361-364

24. Mariette C, Maurel A, Fabre S, Balon JM, Triboulet JP: Preoperative prognostic factors for squamous cell carcinoma of the thoracic esophagus. Gastroenterol Clin Biol 2001, 25:468-472.

25. O'Gilvie AL, Dronfield MW, Ferguson R, Atkinson M: Palliative intubation of esophagogastric neoplasms at fiberoptic endoscopy. Gut 1982, 23:1060-1067.

26. Adenis A, Francois E, Conroy T, Marchal C, Teissier E, Vedrenne B, Seitz JF, Mirabel X, Pignol JP, Resbeut M, Gyselinck N, Brandely M: Phase I study of vinorelbine and concurrent radiation for locally advanced esophageal cancer. ASCO Annual Meeting Proceedings. J Clin Oncol 1999, 18:271.

27. Wider HA, Brücher BL, Zimmermann F, Becker K, Lordick F, Beer A, Schwaiger M Fink U, Siewert JR, Stein HJ, Weber WA: Time course of tumor metabolic activity during chemoradiotherapy of esophageal squamous cell carcinoma and response to treatment. J Clin Oncol 2004, 2:900-908.

28. McLoughlin JM, Melis M, Seagel EM, Dean EM, Weber JM, Chern J, Elliott M, Kelley ST, Karl RC: Are patients with esophageal cancer who become PET negative after neoadjuvant chemoradiation free of cancer? J Am Coll Surg 2008, 206:879-886.

29. Yang Q, Cleary KR, Yao JC, Swisher SG, Roth JA, Lynch PM, Komaki R, Ajani JA, Rashid A, Hamilton SR, Wu TT: Significance of post-chemoradiation biopsy in predicting residual esophageal carcinoma in the surgical specimen. Dis Esophagus 2004, 17:38-43.

30. Minsky BD, Pajak TF, Ginsberg RJ, Pisansky TM, Martenson J, Komaki R, Okawara G, Rosenthal SA, Kelsen DP: Phase III trial of combined-modality therapy for esophageal cancer: high-dose versus standard-dose radiation therapy. J Clin Oncol 2002, 20:1167-1174.

31. Crosby TDL, Brewster AE, Borley A, Perschky L, Kehagioglou P, Court J, Maughan TS: Definitive chemoradiation in patients with inoperable oesophageal carcinoma. Br J Cancer 2004, 90:70-75.

32. Welsh J, Settle SH, Amini A, Xiao L, Suzuki A, Hayashi Y, Hofstetter W, Komaki R, Liao Z, Ajani JA: Failure patterns in patients with esophageal cancer with definite chemoradiation. Cancer 2012, 118:2632-2640.

33. Bedenne L, Michel P, Bouche O, Milan C, Mariette C, Conroy T, Pezet D, Roullet B, Seitz JF, Herr JP, Paillot B, Arveux P, Bonnetain F, Binquet C: 
Chemoradiation followed by surgery compared with chemoradiation alone in squamous cancer of the oesophagus: FFCD 9102. J Clin Oncol 2007, 25:1160-1168.

34. Jouve JL, Michel P, Mariette $C$, Bonnetain F, Bouché $\mathrm{O}$, Conroy T, Pezet $\mathrm{D}$, Burtin $P$, Segol P, Bedenne L: Fédération francophone de cancérologie digestive: outcome of the non randomized patients in the FFCD 9102 trial: chemo-radiation followed by surgery compared with chemoradiation alone in squamous cancer of the esophagus: ASCO Annual Meeting Proceedings. J Clin Oncol 2008, 26:A4555.

35. Mariette C, De Botton ML, Piessen G: Surgery in esophageal and gastric cancer patients: what is the role for nutrition support in your daily practice? Ann Surg Oncol 2012, 19:2128-2134.

doi:10.1186/1471-2407-13-413

Cite this article as: Adenis et al:: Clinical complete responders to definite chemoradiation or radiation therapy for oesophageal cancer: predictors of outcome. BMC Cancer 2013 13:413.

\section{Submit your next manuscript to BioMed Central} and take full advantage of:

- Convenient online submission

- Thorough peer review

- No space constraints or color figure charges

- Immediate publication on acceptance

- Inclusion in PubMed, CAS, Scopus and Google Scholar

- Research which is freely available for redistribution 